\title{
La demanda en forma en la acción pública de inconstitucionalidad
}

\author{
Gustavo Ramírez Núñez \\ Abogado por la Universidad Santo Tomás Bucaramanga, Colombia. Especialista en Derecho Comercial Universidad \\ Libre de Bogotá, Colombia. Especialista en Derecho Constitucional por la Universidad Nacional, Colombia. \\ Especialista en Derecho Probatorio por la Universidad Sergio Arboleda, Colombia. \\ Correo electrónico: gustavoramirezn@hotmail.com
}

\begin{abstract}
Resumen
En el presente trabajo se contextualizan los antecedentes remotos de la acción pública de inconstitucionalidad y su alcance en Colombia a partir del Acto Legislativo 03 de 1910, se estudian los antecedentes del presupuesto procesal de demanda en forma y se hace un análisis de las decisiones publicadas por la relatoría de la Corte Constitucional en su página web sobre inadmisión de la demanda en ejercicio de esta acción entre 1992 y 2012, para denotar que a partir del año 2001 se consolidó la exigencia de unos requisitos mínimos para la presentación de la demanda, los cuales se pueden considerar como el presupuesto procesal de demanda en forma que no desnaturaliza el carácter público de la acción ni interfiere el derecho fundamental de acceso a la administración de justicia.
\end{abstract}

Palabras clave: Derecho procesal constitucional, acción de inconstitucionalidad, presupuestos procesales, demanda en forma, acceso a la administración de justicia.

\begin{abstract}
This work sets remote antecedents of the Public Action of Unconstitutionality in a context and its scope in Colombia as from the Bill 03 of 1910 issued by the Colombian Congress for the modification of constitutional text. The antecedents of prerequisites for an effective lawsuit are studied and an analysis is conducted about the decisions made by the Rapporteurship of the Constitutional Court in its Web page, focusing on the nonadmissibility of the lawsuit while this action was enforceable between the years of 1992 and 2012. This study finds that minimum requirements were set out for the submission of the lawsuit as from the year 2001. These minimum requirements can be considered as the prerequisites for an effective lawsuit court case so the public character of the action is not lost and the fundamental right of having access to the administration of justice is not interferred.
\end{abstract}

Keywords: Constitutional procedural law, unconstitutionality action, court case prerequisites, effective lawsuit, access to administration of justice.

\section{Résumé}

Dans le présent travail à distance l'histoire de l'action publique d'inconstitutionnalité et son champ d'application en Colombie à partir de 1910 la législation 03 contextualiser le dossier de la procédure budgétaire de la demande sont étudiées en forme et une analyse des décisions publiées faites par le rapporteur de la Cour constitutionnelle dans sa page Web sur l'irrecevabilité de la demande dans l'exercice de cette action entre 1992 et 2012 , pour indiquer que de 2001 l'exigence d'exigences minimales pour le dépôt de la poursuite a été jointe, qui peut être considéré comme l'exigence procédurale de la demande d'une manière qui ne dénature pas le caractère public de l'action ou interférer avec le droit fondamental d'accès à la justice . Mots-clés: Droit constitutionnel de procédure, L'action constitutionnelle, Les budgets de procédure, Formulaire de demande, Accès à la justice. 



\section{La demanda en forma en la acción pública de inconstitucionalidad*}

Gustavo Ramírez Núñez

\section{INTRODUCCIÓN}

El Derecho procesal constitucional está compuesto por aquellas normas que regulan los procedimientos que se deben seguir en situaciones concretas como el ejercicio de la acción pública de inconstitucionalidad. La ausencia en Colombia de estudios sobre los requisitos mínimos para el ejercicio de esa acción pública contrasta con el desarrollo que la materia ha tenido en la doctrina extranjera, como el caso peruano donde la existencia de un Código Procesal Constitucional ha fortalecido esa disciplina. De ahí la importancia de asumir el estudio de esos requisitos mínimos, con el fin de determinar si a ellos puede dárseles el calificativo de presupuesto procesal de demanda en forma; si su exigencia desnaturaliza el carácter público de la acción y si se vulnera el derecho de acceso a la administración de justicia.

En Colombia el desarrollo del Derecho procesal constitucional se ha dejado casi por completo a la Corte Constitucional, que a través de su jurisprudencia ha sentado las subreglas de procedimiento y ha interpretado las normas que rigen las acciones constitucionales y los procedimientos que se siguen ante esta Corporación (Decretos 2591 de 1991, 2067 de 1991 y 306 de 1992) para fijar su alcance. El Consejo de Estado, en virtud de la competencia para examinar la constitucionalidad respecto de algunos decretos dictados por el gobierno nacional, también ha hecho lo propio.

La que se conoce como jurisdicción constitucional está integrada no solo por la Corte Constitucional y el Consejo de Estado, sino que además, forman parte de ella todos los jueces y corporaciones judiciales nacionales a quienes les corresponde aplicar los mandatos constitucionales a cada caso concreto, mientras que el control de constitucionalidad en abstracto corresponde a la Corte Constitucional a través de la acción pública de inconstitucionalidad.

Este artículo es producto del trabajo de investigación presentado para optar al título de magíster en Derecho de la Universidad Sergio Arboleda, finalizada en el año 2013. 
Que la especialidad constitucional de la jurisdicción nacional esté conformada por todos los jueces no quiere decir que las decisiones de todos ellos sean la fuente del Derecho procesal constitucional. Lo anterior, solo puede atribuirse a la interpretación de ciertas normas, entre ellas, los Decretos 2591 de 1991, 2067 de 1991 y 306 de 1992 , las Leyes 472 de 1998 y 1095 de 2006 y al desarrollo jurisprudencial que han hecho el Consejo de Estado y la Corte Constitucional con ellas, dado que estas refieren al ejercicio de las acciones, la competencia, la legitimación de las partes, los sujetos procesales, el juez, los principios rectores, la caducidad, las medidas cautelares, entre otros aspectos relativos al procedimiento propio de esta rama casi invisible dentro del derecho procesal: el Derecho procesal constitucional.

Tomando como fuente la página web de la Corte Constitucional, el presente estudio se realizó a partir de los autos publicados por esa Corporación sobre inadmisión de las demandas de inconstitucionalidad presentadas por los ciudadanos en ejercicio de esa acción pública durante los años 1992 y 2012, excluyendo los casos en que las demandas se refieren a vicios de procedimiento (i), sustitución de la constitución por medio de actos legislativos (ii) y los casos en que la Corte se abstiene de admitirlas bajo la égida de la cosa juzgada constitucional (iii) entonces, el estudio abarcó aquellas decisiones emitidas por la Corte Constitucional, en el lapso mencionado, sobre las cuales se hizo un análisis reflexivo. En concreto, de aquellas providencias en las que la Corte Constitucional se refirió a los requisitos mínimos que debe contener la demanda de inconstitucionalidad.

La razón de ser de tales exclusiones radica en que: a) Cuando media la cosa juzgada se releva la Corte de hacer un estudio de fondo de la demanda; b) Cuando el vicio es atribuido a un acto legislativo, la carga argumentativa se incrementa para demostrar la sustitución; y c) Cuando se trata de vicios de trámite el análisis se limita a verificar el procedimiento de creación de la norma y no su contenido. Además, el estudio de estos casos amerita una investigación independiente de la problemática que aquí se aborda.

\section{PLANTEAMIENTO DEL PROBLEMA}

Ahora bien, el planeamiento primordial es si la exigencia en el cumplimiento de unos requisitos mínimos para admitir la demanda de inconstitucionalidad puede adquirir el carácter de presupuesto procesal de la demanda y convertir la acción pública de inconstitucionalidad, nacida para estar al alcance de cualquier ciudadano en un medio técnico y erudito de cuestionamiento de las leyes nacionales, que desdibujaría la intención del constituyente primario plasmada en el artículo 40-6 de la Constitución Política. En este contexto surgen cuestiones como: ¿Hasta dónde llega la exigencia de la Corte Constitucional sobre la forma de la demanda en la acción pública de inconstitucionalidad? O dicho en otras palabras ¿Existe un presupuesto procesal de demanda en forma para la acción pública de inconstitucionalidad? Y 
además, ¿al exigirse el presupuesto procesal de la demanda en forma, se desdibuja la naturaleza pública de la acción?

\section{ORIGEN Y ALCANCE DE LA ACCIÓN PÚBLICA DE INCONSTITUCIONALIDAD}

Pues bien, ¿cuál es el origen y el objetivo de la acción pública de inconstitucionalidad en Colombia? señala Esguerra (2004) que el origen de la acción de inconstitucionalidad no está en la judicial review que fue una creación de la Corte Suprema de Justicia de los Estados Unidos de América con ocasión del célebre fallo dictado el 24 de febrero de 1803 en el caso Marbury Vs. Madison, redactado por el entonces presidente de la Corte John Marshall, pues aquel se trató simplemente de la inaplicación de una norma en un caso concreto. Y, en cambio, se atribuye su origen de acuerdo con el mismo autor, al menos en los Estados de Venezuela y Colombia, a la inclusión en 1858 de la siguiente disposición en la Constitución del país vecino:

Artículo 113. Son atribuciones de la Corte Suprema: [...] $8^{\circ}$. Declarar la nulidad de los actos legislativos sancionados por las Legislaturas Provinciales, a petición de cualquier ciudadano, cuando sean contrarios a la Constitución.

Y en Colombia al Acto Legislativo No. 3 de 1910, como nos cuenta el ilustre compilador Segovia (2010) en Historia de las leyes: Acto Legislativo Número 3 de 1910, después de la discusión en el seno de la Asamblea Nacional Constituyente adoptó como texto definitivo, entre otros, los siguientes artículos:

Artículo 40.- En todo caso de incompatibilidad entre la Constitución y la ley se aplicarán de preferencia las disposiciones constitucionales.

Artículo 41.- A la Corte Suprema de Justicia se le confía la guarda de la integridad de la Constitución. En consecuencia, además de las facultades que le confieren esta y las leyes, tendrá la siguiente:

Decidir definitivamente sobre la exequibilidad de los actos legislativos que hayan sido objetados como inconstitucionales por el Gobierno, o sobre todas las leyes o decretos acusados ante ella por cualquier ciudadano como inconstitucionales, previa audiencia del Procurador General de la Nación.

Entonces, mientras por la vía de la judicial review, solo quien es parte de un proceso judicial puede solicitar en aras de su propio interés, que en el caso concreto no se aplique una ley por considerarla contraria a la Constitución; en los ordenamientos jurídicos de Venezuela y Colombia cualquier ciudadano podía demandar, en cualquier momento, la anulación para todo y para todos de la ley. Lo anterior, quiere decir que en el primer caso, los efectos son inter-partes y, en el segundo, erga omnes. 
Dejando de lado el importante antecedente venezolano y concentrándonos en el caso colombiano, se puede afirmar que a partir de este momento (1910) se le da a la acción de inconstitucionalidad el carácter de pública, toda vez que pone en manos de los ciudadanos la facultad de cuestionar al legislador y someter a juicio de la autoridad judicial las leyes elaboradas por aquel, en perjuicio de la presunción de constitucionalidad que las cobija. Asegurando así la supremacía de la Constitución. Ese matiz popular de la acción pública de inconstitucionalidad se mantuvo en la promulgación de la Constitución Política de 1991 (CP) tal como se deduce de su artículo 241. Esta disposición normativa hace que cualquier ciudadano continúe, en la actualidad, sometiendo las leyes y las actuaciones del Congreso en el proceso de su formación al juicio de constitucionalidad, eso sí, previo cumplimiento de unas exigencias formales como se verá más adelante.

Por lo anterior, la acción pública de inconstitucionalidad propende por una labor de hermenéutica jurídica bastante compleja para la Corte Constitucional dada la textura abierta de las disposiciones constitucionales. De acuerdo con el artículo 241 $\mathrm{CP}$, se le confía a la Corte la guarda de la integridad y supremacía de la Constitución, función que debe cumplir -entre otros casos- al decidir sobre las demandas de inconstitucionalidad que presenten los ciudadanos contra las leyes. Es decir, se busca que la Corte diga si la norma se ajusta o no al articulado Carta Política, orientada por unos principios que se pueden sintetizar de la siguiente manera parafraseando a Zuñiga (2010):

El principio de la supremacía de la Constitución, según el cual un precepto constitucional sólo se reforma o queda derogado cuando se emite otro de idéntico valor jerárquico; el principio de la efectividad constitucional por el que ante varias interpretaciones posibles debe optarse por la que más favorezca la efectividad del texto superior; el principio de unidad constitucional en virtud del cual el articulado del texto superior debe entenderse en su totalidad respetando el preámbulo, la parte dogmática y orgánica y en general todos los valores consignados en la Constitución; la consideración al sistema político adoptado por la Constitución que, en nuestro caso, es el Estado social de derecho; el respeto al precedente, es decir la coherencia argumentativa con otros fallos constitucionales; la consideración al impacto que puedan tener los fallos constitucionales; la exigencia de una motivación suficiente en las decisiones; $y$, por último, el principio conservacionista, que tiene que ver con la presunción de constitucionalidad de las leyes en donde la declaratoria de inconstitucionalidad debe ser la última ratio.

\section{LOS PRESUPUESTOS PROCESALES Y LA DEMANDA EN FORMA}

La teoría de los presupuestos procesales surge con la publicación del procesalista alemán Bon Bülow (2008) sobre la "Teoría de las excepciones procesales y los presupuestos procesales" (1868) en donde se esfuerza por hacer la diferenciación 
entre las excepciones referidas a la capacidad dispositiva de las partes y los presupuestos procesales referidos a las condiciones necesarias para la constitución de la relación jurídica procesal. Los segundos, concluye el autor, deben ser controlados oficiosamente por el juez, es decir, sin necesidad de alegación por el demandado. Posteriormente, Calamandrei (1973) en su obra Instituciones de Derecho Procesal Civil según el nuevo Código (1915) se refiere a presupuestos procesales como las condiciones que deben existir a fin de que pueda tenerse un pronunciamiento favorable o desfavorable sobre la demanda, agregando que son requisitos para la constitución y desarrollo de la relación procesal. Y más tarde, Goldschmidt (1936) los calificó como supuestos de la sentencia de fondo cuya ausencia no impiden el nacimiento del proceso.

En América Latina, Vescovi (2006) los define como: "los requisitos necesarios para que pueda constituirse un proceso válido, o una relación procesal válida" ( $\mathrm{p}$. 80). El profesor Devis (2009) se refirió a ellos como los requisitos determinantes para el nacimiento válido del proceso y su normal terminación con la sentencia cuya inobservancia generalmente vicia de nulidad el proceso.

Entonces, se debe entender por presupuestos procesales como los requisitos mínimos para la constitución válida de la relación jurídico procesal, que son considerados como necesarios para que pueda desarrollarse válidamente el proceso judicial -cualquiera que sea su naturaleza, no solo constitucional-. Estos determinan el normal desenvolvimiento del proceso con miras a su culminación normal mediante la sentencia que decida de fondo el asunto propuesto - en nuestro caso de estudio, la constitucionalidad de las leyes-.

Si bien la concurrencia de los presupuestos procesales no garantiza el éxito de la pretensión, sí permite el debido ejercicio de la acción. La doctrina reconoce como presupuestos procesales la jurisdicción, la competencia, la capacidad procesal, la capacidad para ser parte y la demanda en forma. Los primeros no presentan inconveniente alguno en el ejercicio de la acción pública de inconstitucionalidad, pues como indica el artículo 241 C.P., a la Corte Constitucional se le confía la guarda de la integridad y la supremacía de la Constitución y, en ejercicio de esa función, conoce de las demandas de inconstitucionalidad presentadas por los ciudadanos contra las leyes por su contenido material. Tales presupuestos se satisfacen cuando el ciudadano en ejercicio -entiéndase cumplida la mayoría de edad, que indica su capacidad-, presenta la demanda ante la Corte Constitucional. Por el contrario, la demanda en forma se refiere al hecho concreto de que el libelo reúna los requisitos exigidos en los estatutos procedimentales. 
En efecto, si la demanda no reúne esos requisitos mínimos y el juez no ordena su corrección al momento de fallar, se debe inhibir para dictar sentencia de fondo, de ahí que en los casos estudiados la Corte Constitucional inadmitiera las demandas por aspectos de forma, sin que ello implique la violación del derecho de acceso a la administración, porque el ciudadano cuenta con la posibilidad de volver a presentar la demanda, pese a que habrá perdido su trabajo y se encontrará con una barrera que parece desnaturalizar la acción.

El análisis preliminar, a partir de la interposición de toda demanda, recae sobre sus presupuestos procesales, la Corte Constitucional considera su competencia e incompetencia y hace un estudio sobre la carga argumentativa que contiene el libelo con el fin de determinar si puede conducir a una sentencia de fondo o a su inhibición. Si bien no se trata de un prejuzgamiento, sí se trata de la revisión de los presupuestos mínimos, antes referidos, que debe tener todo proceso a punto de iniciarse, y que tienen la característica de ser revisables y exigibles de oficio por el juez en razón de estar vinculados con la validez del proceso, como señala el profesor Devis (1979).

Como el examen de inconstitucionalidad que aquí nos interesa es el promovido por el ciudadano, la demanda resulta de absoluta relevancia, toda vez que la acción está en manos de aquel, pero debe materializarla a través de un escrito formal, de ahí que la demanda constituya como dice el profesor López (2009): "el instrumento que el Estado pone en manos del asociado para ejercer el derecho subjetivo personalísimo de acción", que en el caso de la demanda de la inconstitucionalidad, se debe reunir los requisitos formales que están señalados en el artículo 2 del Decreto 2067 de 1991.

Entonces, en el control de constitucionalidad promovido por el ejercicio ciudadano de la acción pública de inconstitucionalidad, se debe considerar una serie de requisitos procesales que deben cumplirse para que la demanda sea estudiada de fondo por la Corte Constitucional y pueda obtenerse un pronunciamiento que no sea inhibitorio. El primero es la indicación de las normas señaladas como inconstitucionales, para lo cual basta su trascripción literal o anexar un ejemplar de la publicación oficial; el segundo requisito lo constituye el señalamiento de las normas superiores que se consideran infringidas por la o las disposiciones demandadas; el tercero exige las razones por las cuales esos preceptos constitucionales se consideran violados; el cuarto se refiere al caso específico cuando la demanda está motivada por vicios de trámite en la formación de las normas y consiste en el señalamiento expreso del trámite impuesto por la Constitución para la expedición del acto demandado y la forma en que fue infringido; el quinto requisito exige indicar la razón por la cual la Corte es competente para conocer la demanda. Este último presupuesto procesal de la competencia no se puede afirmar que sea baladí, pues recordemos que parte del control de constitucionalidad lo ejerce el Consejo de Estado.

Si bien estas cinco exigencias del artículo 2 del Decreto 2067 de 1991 parecen ser en principio nada más que el desarrollo de una técnica para la presentación de la demanda, la tercera de ellas entraña la materialización de un verdadero presupuesto procesal, que en la doctrina se denomina como "la demanda en forma". Sobre la 
exigencia de esa enunciación de las razones por las cuales los textos señalados de la constitución se estiman violados, se construyó toda una teoría en diferentes pronunciamientos de la Corte Constitucional que en síntesis exige que las razones en que se fundamentan los cargos de inconstitucionalidad formulados sean: claras, ciertas, especificas, pertinentes y suficientes.

\section{EL DERECHO DE ACCESO A LA ADMINISTRACIÓN DE JUSTICIA}

En palabras de la Corte Constitucional este derecho no puede concebirse como la simple posibilidad formal de llegar ante los jueces o en la existencia de una estructura judicial que reciba las demandas de los asociados, sino que su esencia radica en la certidumbre de que ante los estrados judiciales serán surtidos los procesos con aplicación del orden jurídico vigente, con la objetividad y suficiencia probatoria que aseguren un real y ponderado conocimiento del juez sobre los hechos materia de decisión, como señaló la Corte Constitucional en Sentencia T-055 de 1995 con reiteración en la C-1027 de 2012. Para garantizar el ejercicio de este derecho, el actor cuenta con la posibilidad de subsanar la demanda y su nueva argumentación no satisface las exigencias del magistrado sustanciador que dispone del recurso de súplica con el que se garantiza el acceso a la administración de justicia.

Asimismo, la tutela judicial efectiva, que consiste en la garantía que tienen los ciudadanos para obtener un pronunciamiento de fondo sobre las cuestiones que son planteadas a la jurisdicción, no puede ser exigido sin contraprestación alguna, pues no todo líbelo demandatorio tiene la vocación para obtener ese pronunciamiento, pues como se ve en la práctica judicial no toda pretensión puede ser atendida si no se ofrecen razones suficientes para su éxito, por lo que las exigencias de la Corte Constitucional no resultan exageradas.

\section{LAS EXIGENCIAS DE LA CORTE CONSTITUCIONAL}

La fase investigativa que comprendió la revisión de los autos proferidos entre 1992 y 2012, publicados por la relatoría de la Corte Constitucional a través de su página web, arrojó que: durante los primeros nueve años de vida de la Corte Constitucional no se presentaron mayores hallazgos sobre inadmisión, lo que permite inferir flexibilidad en materia de admisión de las demandas, lo que se revalida con un alto número de sentencias inhibitorias proferidas en esa misma época. Tan solo en el auto 017 de 1992 se inadmitió la demanda bajo la indicación genérica de que el demandante no cumplió con el requisito exigido por el artículo 2 del numeral 3 del Decreto 2067 de 1991, porque no presentaba ni un solo argumento para sustentar que las normas demandadas vulneraban la Constitución.

En 1997 en el Auto 024, la Corte sostuvo la siguiente tesis: que una demanda de inconstitucionalidad no satisface el requisito contemplado en el numeral 3 del artículo 
2 del Decreto 2067 de 1991 cuando: "Los argumentos del actor son el resultado de una elucubración general, es decir, de una formulación vaga, abstracta y global de los motivos de inconstitucionalidad" y ratificó la inadmisión de la demanda diciendo: "El trámite de la acción pública solo puede adelantarse cuando efectivamente haya habido demanda, esto es una acusación de un ciudadano contra una norma legal y con base en disposiciones constitucionales efectivamente vigentes".

Se empieza a observar tenuemente en el año referido, la exigencia del presupuesto procesal de demanda en forma dentro de la acción de inconstitucionalidad, pese a no denominarlo de esa forma, como sí lo hizo más adelante. En el periodo comprendido entre 1997 y 2000 no presentaron hallazgos sobre inadmisión de la demanda por falta de argumentación en los cargos formulados.

Ya en el año 2001 en el auto 244, se dejó en firme la inadmisión de la demanda bajo la afirmación que no tenía cargos específicos, claros pertinentes, suficientes y de carácter constitucional y se dijo, por primera vez, que cuando no se cumplen estos requisitos mínimos se debe inadmitir la demanda. Posteriormente, en el Auto 314 de 2001 concretamente la Corte exige del accionante un deber mínimo de diligencia en la confección de la demanda en virtud del carácter rogado y no oficioso de la acción de inconstitucionalidad, señalando que el trámite de la acción solo puede adelantarse cuando efectivamente haya habido demanda, es decir, otra alusión al presupuesto procesal de la demanda en forma.

No obstante, la investigación recayó sobre los autos del periodo referido; en el año 2001 se profirió la sentencia C-1052 que excepcionalmente debió analizarse por su amplia citación en los autos de los años siguientes hasta el 2012. Dicha sentencia se refirió con mayor amplitud a los requisitos mínimos ya mencionados y los formuló como claridad, certeza, especificidad, pertinencia y suficiencia, que fueron desarrollados así:

La claridad, que se espera de toda demanda - no solo de las demandas de inconstitucionalidad- consiste en tener un hilo conductor en la argumentación que le permita al lector comprender su contenido y las razones en que se basa la pretensión; sin que ello implique hacer una exposición erudita y técnica, merced al carácter especial de esta acción que fue diseñada para estar al alcance de cualquier ciudadano. Además de que las razones claras en que se basa el (o los) cargo (s) de inconstitucionalidad, se requiere que recaigan sobre una proposición jurídica real y existente y no sobre una deducida por el actor o implícita, o sobre otras normas concordantes que no son objeto real de la demanda, es decir, que se trate de normas ciertas dictadas por el legislador cuyo contenido debe contrastarse con la norma superior, que es a lo que se refiere el requisito de certeza.

La especificidad hace alusión a que se rechaza toda vaguedad, indeterminación, abstracción o generalidad. De ahí que el cargo debe apuntar a demostrar si realmente existe una oposición objetiva y verificable entre el contenido de la ley y la constitución.

La pertinencia, por su parte, alude a que el reproche formulado sea de naturaleza constitucional, es decir, basado en la apreciación de una norma constitucional y la 
forma como se enfrenta a la ley demandada; dicho en otras palabras no se admiten cargos basados en consideraciones legales, doctrinarias o puramente subjetivas del actor. A modo de ejemplo, la Corte ilustra la impertinencia con la solicitud de inexequibilidad de la norma para un caso específico, o su simple calificación como inocua o innecesaria.

La suficiencia consiste en la capacidad argumentativa y probatoria que se exige del actor, en otras palabras, la demanda no solo debe generar una duda sobre la inconstitucionalidad del precepto demandado, sino debe convencer al magistrado sustanciador y ofrecer argumentos serios que desvirtúen la presunción de constitucionalidad de la ley demandada.

A partir del 2001 con la emisión de la sentencia referida, se consolidó la exigencia de la Corte en el sentido que la demanda debe presentar una argumentación clara, cierta, concreta, pertinente y suficiente para despertar la duda sobre la inconstitucionalidad, si se quiere que esta sea admitida. Esta exigencia se reiteró en los autos 096 y 196 de 2002, 125 y 178 de 2003, 049, 113 y 114 de 2004. En el año 2005, en el auto 010 justificó que la inadmisión por incumplimiento de esos requisitos racionaliza el ejercicio de la acción y mantuvo la exigencia antes mencionada como se observó en los autos 031, 032, 033, 062, 063 de ese mismo año. Esta tendencia desembocó en el auto 064 de 2005 en el que se ratificó la no revisión oficiosa de la constitucionalidad de las leyes, y se incorporó expresamente la existencia del presupuesto procesal de demanda en forma para la acción pública de inconstitucionalidad. Dicha postura se compagina con la emisión del Auto 148 de 2006 que calificó como presupuestos procesales los requisitos del artículo 2 de Decreto 2067 de 1991, norma en la que se basó la creación jurisprudencial de tales requisitos.

Sistematizados esos requisitos de claridad, certeza, especificidad, pertinencia y suficiencia que, según la Corte, no pasan de ser una exigencia mínima, se continuó exigiéndolos en autos como los 187 y 244 de 2007, 025, 132, 161 y 300 de 2008, 240, 251, y 263 de 2009, 012, 081, 323, 324 de 2010, 052, 053, 116, 117 y 254 de 2011, 073, 158 y 174 de 2012, pero esta exigencia en realidad constituyen un verdadero presupuesto procesal: el de demanda en forma, como se verá a continuación.

La razón para entenderlo como una verdadera exigencia del presupuesto procesal de la demanda en forma es que la falencia de la demanda, cuando esta no se muestra clara, cierta, específica, suficiente y pertinente, generó su inadmisión bajo el argumento de su no conducencia hacia una sentencia de fondo como se observó en los casos estudiados, y en caso de no subsanarse tal falencia dentro del término oportuno, se deriva en el rechazo e impide el surgimiento de la relación jurídico procesal. Con lo cual el actor, independientemente de que sea ilustrado en materia jurídica o ciudadano común, habrá perdido su trabajo al no resistir su argumentación un primer análisis.

Un excesivo rigorismo en el examen del presupuesto procesal de "la demanda en forma" o de esos requisitos mínimos como los denomina la Corte en la acción pública de inconstitucionalidad, generaría una barrera que soslaya el derecho de acceso a 
la administración de justicia, porque impondría cargas desproporcionadas para el ciudadano común, profano en asuntos jurídicos que vería limitada su posibilidad de utilizar un instrumento de la democracia participativa, que está instituido para el control del poder político y la garantía de la supremacía constitucional. Pero es cierto que la exigencia de esos requisitos racionaliza el ejercicio de la acción y aumenta su efectividad cuando se cumple con esa carga procesal en el acto de introducción.

En efecto, una de las aristas del derecho de acceso a la administración de justicia entraña la prohibición de establecer obstáculos que impidan que se produzca una decisión de fondo, puesto que no solo se reconoce conforme a este derecho fundamental la posibilidad formal de que la persona acuda ante la Jurisdicción establecida por el Estado dentro de su organización política, sino que también surge un deber correlativo de los funcionarios judiciales de remover los obstáculos que impidan el proferimiento de la decisión de fondo, con la finalidad de garantizar que se materialice el derecho en comento y no se vea reducido a un aspecto formal o nominal.

Resulta entonces de gran importancia conocer las exigencias mínimas -antes sintetizadas-que la Corte Constitucional creó a través de su jurisprudencia, y que se asuma que a pesar de la informalidad que caracteriza las acciones constitucionales, en materia de la acción pública de inconstitucionalidad, se debe satisfacer el presupuesto procesal de la demanda en forma, pues ni siquiera la aplicación del principio pro actione permite pasarlo por alto, ya que el control de constitucionalidad de las leyes, como señaló la Corte Constitucional no se ejerce de manera oficiosa por parte de esa Corporación y, por ende, el ciudadano demandante debe esgrimir una argumentación sólida para propiciar un verdadero debate de constitucionalidad.

\section{CONCLUSIONES}

A partir del año 2001 con emisión de la sentencia C-1052 se consolidó la exigencia de unos requisitos para la admisión de la demanda de inconstitucionalidad que pueden ser calificados como el presupuesto procesal de demanda en forma, porque pese a darle el nombre de requisitos mínimos, su concurrencia está justificada en la necesidad que encarnan para el nacimiento del proceso y su satisfacción fue reclamada por el magistrado sustanciador en todos los casos estudiados como presupuesto necesario para la emisión de una sentencia de fondo.

La exposición de los cargos de inconstitucionalidad con claridad, certeza, especificidad, pertinencia y suficiencia, a las que reiteradamente se ha referido como requisitos mínimos, es necesaria para trabar la relación jurídica procesal entre el actor y los demás intervinientes en el proceso judicial, quienes frente a una argumentación satisfactoria pueden ejercer la controversia o coadyuvar efectivamente con la solicitud de declaratoria de inexequibilidad y así el Juez - en este caso colegiado- contará con un verdadero concepto de violación. 
Si bien la exigencia se consolidó en el año 2001, la Corte solo utilizó expresamente el término demanda en forma en el auto 064 de 2005 y no volvió a utilizarlo en los autos de los posteriores, por eso no podemos hablar de un periodo de exigencia tácita del presupuesto procesal de la demanda en forma y otro de exigencia expresa, pues salvo ese caso puntual, la exigencia de la demanda en forma siempre ha sido tácita bajo la nominación de requisitos mínimos.

Un excesivo rigor en la verificación del cumplimiento de esos requisitos mínimos que no dudo en llamar "demanda en forma" puede generar la pérdida de eficacia de la acción pública de inconstitucionalidad, al despojar al ciudadano común de una posibilidad real de obtener un pronunciamiento de fondo por parte de la Corte Constitucional, reduciendo el espectro real de los demandantes constitucionales que no tengan formación jurídica, pero en la práctica la exigencia no llega al extremo de interferir con el derecho fundamental de acceso a la justicia, porque el actor cuenta con la posibilidad de promover nuevamente la demanda con la argumentación exigida en el auto de inadmisión, mientras que la exigencia oficiosa por parte del juez de la demanda en forma, o la satisfacción de esos requisitos mínimos, sí son el punto de partida para la constitución válida de la relación jurídica procesal que hace efectivo el derecho de acceso a la justicia, por lo que comparto plenamente la exigencia de la Corte Constitución en cuanto al presupuesto procesal mencionado para la acción pública de inconstitucionalidad.

\section{REFERENCIAS}

Bon Bülow, O. (2008). Teoría de las excepciones y los presupuestos procesales. Buenos Aires: El Foro.

Calamandrei, P. (1973). Instituciones de derecho procesal civil. Buenos Aires: Ediciones Jurídicas.

Colombia. Asamblea Nacional Constituyente (1991). Constitución Política de Colombia.

Colombia. Corte Constitucional. Auto 017. M.P. Hernández Galindo, J.G. Bogotá, julio, 1992.

Colombia. Corte Constitucional. Auto 024. M.P. Cifuentes Muñoz, E. Bogotá, julio, 1997.

Colombia. Corte Constitucional. Auto 244. M.P. Córdoba Triviño, E. Bogotá, julio, 2001.

Colombia. Corte Constitucional. Auto 314. M.P. Tafur Galvis, A. Bogotá, diciembre, 2001.

Colombia. Corte Constitucional. Auto 096. M.P. Vargas Hernández, C.I. Bogotá, julio, 2002. 
Colombia. Corte Constitucional. Auto 196. M.P. Escobar Gil, R. Bogotá, agosto, 2002.

Colombia. Corte Constitucional. Auto 125. M.P. Araujo Rentería, J. Bogotá, julio, 2003.

Colombia. Corte Constitucional. Auto 178. M.P. Montealegre Lynett, E. Bogotá, octubre, 2003.

Colombia. Corte Constitucional. Auto 049. M.P. Tafur Galvis, A. Bogotá, abril, 2004.

Colombia. Corte Constitucional. Auto 113. M.P. Vargas Hernández, C.I. Bogotá, agosto, 2004.

Colombia. Corte Constitucional. Auto 114. M.P. Uprimny Yepes, R. Bogotá, agosto, 2004.

Colombia. Corte Constitucional. Auto 010. Escobar Gil, R. Bogotá, enero, 2005.

Colombia. Corte Constitucional. Auto 031. Araujo Rentería, A. Bogotá, febrero, 2005.

Colombia. Corte Constitucional. Auto 032. Araujo Rentería, A. Bogotá, febrero, 2005.

Colombia. Corte Constitucional Auto 033. Tafur Galvis, A. Bogotá, febrero, 2005.

Colombia. Corte Constitucional. Auto 062. Tafur Galvis, A. Bogotá, abril, 2005.

Colombia. Corte Constitucional. Auto 063. M. P. Tafur Galvis, A. Bogotá, abril, 2005.

Colombia. Corte Constitucional. Auto 064. M.P. Tafur Galvis, A. Bogotá, abril, 2005.

Colombia. Corte Constitucional. Auto 148. M.P. Tafur Galvis, A. Bogotá, mayo, 2006.

Colombia. Corte Constitucional. Auto 187. M.P. Araujo Rentería, J. Bogotá, julio, 2007.

Colombia. Corte Constitucional. Auto 244. M.P. Araujo Rentería, J. Bogotá, agosto, 2007.

Colombia. Corte Constitucional. Auto 025. M.P. Vargas Hernández, C. I. Bogotá, febrero, 2008.

Colombia. Corte Constitucional. Auto 132. M.P. Vargas Hernández, C. I. Bogotá, mayo, 2008.

Colombia. Corte Constitucional. Auto 161. M.P. Cepeda Espinosa, M. J. Bogotá, julio, 2008.

Colombia. Corte Constitucional. Auto 300. M.P. Cepeda Espinosa, M. J. Bogotá, noviembre, 2008.

Colombia. Corte Constitucional. Auto 240. M.P. Palacio Palacio, J. I. Bogotá, julio, 2009.

Colombia. Corte Constitucional. Auto 251. M.P. González Cuervo, M. Bogotá, julio, 2009. 
Colombia. Corte Constitucional. Auto 263. M.P. Vargas Silva, L. E. Bogotá, agosto, 2009.

Colombia. Corte Constitucional. Auto 012. M.P. González Cuervo, M. Bogotá, febrero, 2010.

Colombia. Corte Constitucional. Auto 081. M.P. Mendoza Martelo, G. E. Bogotá, mayo, 2010.

Colombia. Corte Constitucional. Auto 323. M.P. Pretelt Chaljub, J. I. Bogotá, septiembre, 2010.

Colombia. Corte Constitucional. Auto 324. M.P. Pretelt Chaljub, J. I. Bogotá, septiembre, 2010.

Colombia. Corte Constitucional. Auto 052. M.P. González Cuervo, M. Bogotá, marzo, 2011.

Colombia. Corte Constitucional. Auto 053. M.P. Mendoza Martelo, G. E. Bogotá, marzo, 2011.

Colombia. Corte Constitucional. Auto 116. M.P. Palacio Palacio, J. I. Bogotá, junio, 2011.

Colombia. Corte Constitucional. Auto 117. M.P. Mendoza Martelo, G. E. Bogotá, junio, 2011.

Colombia. Corte Constitucional. Auto 254. M.P. Sierra Porto, H. A. Bogotá, noviembre, 2011.

Colombia. Corte Constitucional. Auto 073. M.P. Palacio Palacio, J. I. Bogotá, marzo, 2012.

Colombia. Corte Constitucional. Auto 158. M.P. Sierra Porto, H. A. Bogotá, julio 2012.

Colombia. Corte Constitucional. Auto 174. M.P. Mendoza Martelo, G. E. Bogotá, julio, 2012.

Colombia. Corte Constitucional. Sentencia C-1052. M. P. Cepeda, Espinosa, M. J. Bogotá, 4 de octubre, 2001.

Congreso de la República de Colombia (1998). Ley 472. 5 de agosto.

Congreso de la República de Colombia (2006). Ley 1095. 2 de noviembre.

Congreso de la República de Venezuela (1858). Constitución de la República de Venezuela.

Devis, H. (1979). Compendio de derecho procesal. Bogotá: ABC.

Devis, H. (2009). Instituciones de derecho procesal civil colombiano. Bogotá: Dupre. Esguerra, P. J. (2004). La protección constitucional del ciudadano. Bogotá: Legis. Goldschmidt, J. (1936). Derecho procesal civil. Madrid: Labor.

López, B. H. (2009). Instituciones de derecho procesal civil colombiano. Bogotá: Dupre.

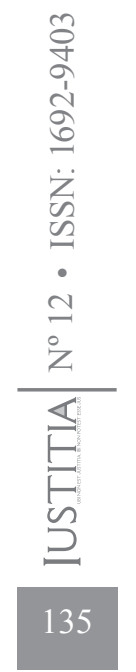


Presidencia de la República de Colombia (1991). Decreto 2067.

Presidencia de la República de Colombia (1991). Decreto 2591.

Presidencia de la República de Colombia (1992). Decreto 306.

Segovia, L. (2010). Historia de las leyes. Acto Legislativo número 3 de 1910. Bogotá: Academia Colombiana de Jurisprudencia.

Vescovi, E. (2006). Teoría general del proceso. Bogotá: Temis.

Zuñiga, B. G. (2010). De la interpretación legal a la interpretación constitucional. Bogotá: Ibañez. 